\title{
Exchanges
}

In the Exchanges, we present conversations with scholars and practitioners of community engagement, responses to previously published material, and other reflections on various aspects of community-engaged scholarship meant to provoke further dialogue and discussion. We invite our readers to offer in this section their own thoughts and ideas on the meanings and understandings of engaged scholarship, as practiced in local or faraway communities, diverse cultural settings, and various disciplinary contexts. We especially welcome community-based scholars' views and opinions on their collaboration with university-based partners in particular and on engaged scholarship in general.

\section{Community-University Partnerships for Social Justice: An Interview with Joan Kuyek}

In this section, co-editor of this issue Nancy Van Styvendale interviews Joan Kuyek, an Ontario-based social and environmental justice activist with nearly fifty years of experience as a community organizer and educator. Joan has been involved in a wide range of projects, including Better Beginnings, Better Futures (as Founding Program Coordinator), which develops programming for children and families in a low-income neighbourhood in Sudbury; MiningWatch Canada (as founding National Coordinator), an organization that works with community interests to educate the public about and influence policy on mining practices; and, most recently (as Chair), the GottaGo! campaign seeking action toward a network of public toilets in Ottawa. She was shortlisted for Samara's Everyday Political Citizen of the Year ("EPCitizen") Award in 2015, which nationally recognizes citizens who are participating in Canadian democracy by enriching public life in the country. In addition to her book Community Organizing: A Holistic Approach (2011), she has contributed a co-authored piece on the Northeastern Ontario Women's Conference to the collection Changing Lives: Women in Northern Ontario (1996), has authored several digital publications on mining economies and mining waste, and has also published on the impacts of mining on women's health in Canadian Woman Studies (Fall 2003/Winter 2004). In 1995, she received an Honourary Doctorate of Social Work from Laurentian University for her community activities. Currently, she teaches at the School of Social Work at Carleton University in Ottawa.

Drawing, in particular, on Joan's rich history working with universities and researchers on community-based projects, the interview discusses the realities, challenges, and benefits of such community-university partnerships, including the more specific experience of working with faculty and students involved in community service-learning (CSL). 
Nancy Van Styvendale: Hi Joan, it's an honour to speak with you today. Perhaps you could begin by sharing a bit about how you first got involved in community-university partnerships.

Joan Kuyek: I started out in community work in the mid-1960s when I was part of a Student Union for Peace Action project called the Kingston Community Project. That project worked closely with people from the university. It was in the low-income communities. We raised our own money to do it and we worked with activists in the university who wanted to change the way the university was set up, or how the power worked there, and who wanted to make it available to the people who weren't of the class that ended up in the university.

One of the projects we worked on was trying to change the Landlord and Tenant Act. In doing that, we- "we" being the Kingston Community Project and what became the Association for Tenants' Action Kingston-had a lot of back-and-forth between university colleagues and ourselves, including drafting a bylaw for presentation to city council and working on rent control. We were very much colleagues working together to make these changes happen. There wasn't a sense that this was a university-paid-for project. I don't think any of the people we were working with were actually paid by the university or by a grant. They did it because they believed in it. That's informed how I look at a lot of things.

Nancy: Could you say more about why you do this work with universities? What are your personal motivations, or the motivations of the organizations or groups you've worked with?

Joan: The first question I always have about community engagement or community-university partnerships is: why are we doing this? What values is it based on? I think that's often missing in the discussion about community-university partnerships. "Community" is a word that can mean anything. Often, it's used to camouflage differences in class, race, or gender. Certainly, it doesn't, in and of itself, talk to the issues of how power is distributed in a neighbourhood. It can mean a locality, it can mean a group of people with similar interests, and it can mean a neighbourhood. There's a whole lot of unpacking that has to happen to make any of this work.

The same thing is true about the university. The university is an institution that replicates power relationships in society. Most work that's done at universities is not to empower grassroots people, it's to serve elites. University people who want to involve themselves in social change face enormous obstacles, from getting money, to getting tenure, to being able to speak as they want to their students.

Nancy: Do you feel like that question of “why?” isn't asked as much as it should be?

Joan: I don't think it's ever asked. Or, a lot of people ask "why?" but it's never the presenting 
question at the beginning. Everybody has good motivations. It's just that the discussion of power relationships, particularly in the university, is not explicit, and if you don't make it explicit, then it's hidden, and it operates in all sorts of ways we don't expect.

Nancy: What are your observations, then, about the ways in which the university works with or engages community and community partners? Are there strengths or weaknesses to these approaches?

Joan: One thing that often happens is you usually have fairly senior academics involved in developing the community partnerships because those are the people who can get the money, through SSHRC [Social Sciences and Humanities Research Council] or elsewhere. They have to find money to do these projects, so the project gets shaped by the funder.

For example, with SSHRC, it's really about providing jobs for graduate students, to be quite frank. SSHRC-funded projects provide status for senior academics and jobs for graduate students. There are wonderful community-based SSHRC projects, but the academics who do them are up against enormous opposition of various kinds to make them happen. There are the accounting systems that don't easily get money to community groups unless they are a registered charity. The graduate students aren't paid enough. As an academic, you have to publish, and it has to be in a peer-reviewed academic journal. The work being done in the community is then written up in a language and form that the neighbourhood doesn't even necessarily understand or see. The pressures on academics, which you'd know really well, are enormous these days. To do a project well that isn't part of the core mandate of the university is incredibly difficult.

One of the projects I was involved with for years was Better Beginnings, Better Futures in Ontario. I was an activist in Sudbury, where we got one of the Better Beginnings projects in partnership with Laurentian [University]. It was a community-university partnership funded by the government of Ontario. The Ontario government chose, through competition, eleven disadvantaged neighbourhoods in Ontario to measure the effectiveness of community-based early intervention (i.e. programming to compensate for poverty and other disadvantages) with children who were either in the $0-4$ or 4-8 category, and they planned to do a 25-year longitudinal study of the impact of these interventions. I was the Program Coordinator in the community who had to put the project together.

It was a really useful project, and it went along quite swimmingly until Mike Harris got elected and they cancelled the research component of the program. The results were still good, and there were all sorts of things that we learned from that experience. The parents were deeply involved in designing what would happen. The researchers did annual interviews with the parents of the kids, and the children went through a development measuring standard, so it was all done very respectfully. The parents loved having the research happen.

The place where there was the most tension was that the academics involved were under enormous pressure to show results from the research before we were ready. We 
constantly battled over the ability of the neighbourhood to take the project where we wanted it to go and over the requirements of the funders. That was difficult. For example, the kids got older. People wanted to be working with pre-teens. But there was no money for pre-teens, and in the neighbourhood, the fact that the project was for 4-8-year-olds didn't make much sense.

There was also some tension over publications about the neighbourhood, although most people in the community didn't even know it was happening. That was fairly restricted to those of us who were more aware of what was going on. And there were a lot of problems around whose time got used. Although I thought the research was important, the demands of trying to run a community-based project with almost no money and a huge staff in that situation were so great that I ended up resenting almost every minute I had to spend discussing research objectives with the university. I think that often happens.

I hated feeling that way, but I did. I'd have a meeting with the academics and they'd want to discuss details and get us involved because we were supposed to help shape the research. I didn't even understand what they were talking about half the time, and I teach at the university as a contract instructor. I'm not ignorant, I just didn't have the interest in the details of the research that they did. I found that with other projects, too. The things we're interested in are different. And as the researchers came to be under so much pressure and the research looked like it was going to be cut, they wanted us to advocate for the research, which was another pressure. And we knew the only way to get money for the community was through the research.

Nancy: In one of the community-based projects I'm involved in, we struggle with knowing that if we're going to get money for the project, it's going to be research money. But what we really need is money for our program first. That's the most important thing for us.

Joan: I'm sure it is, but you know that you can't move it there. There's also the issue of community partners getting paid in a timely fashion. Community groups can't wait for months for money. And the sources of funding for politically charged community groups are particularly limited. It's hard for anybody doing any kind of social and community service, but if you're trying to do anything that involves political change and you can't get a charitable number, you're screwed. Grant money can be paid to a charitable partner or an individual, but not to a community group that isn't incorporated. You won't get money anywhere. That's a huge issue in these partnerships.

I worked for a legal clinic in Sudbury for seven years as a community legal worker. There were a number of projects we tried to do to help welfare recipients, injured workers, and low-income tenants through the university at that time. The legal clinic had charitable status, thank God, and was able to sponsor projects. We'd get student placements, but at the legal clinic, a placement was not a great idea because we had so little time. I had to manage 150 case files and a community-organizing file, plus I was expected to supervise any placements we got. If they made a mistake, it was really serious. 
You had to be watching them all the time, because even though they might be really good, you didn't know that until you had supervised them. The time commitment to look after a placement was just too dangerous for us. We couldn't do it.

Nancy: Yes, that's an important issue. From a community perspective, what are some other limitations or benefits to working with students in CSL or other community-engaged learning contexts?

Joan: The same thing happened when I came to Ottawa in 1999 as the founding national coordinator of MiningWatch Canada. We took on some student placements, but we had to be careful that they had a discreet project that we might end up not using later on. We couldn't integrate them into the work of the organization until we had the finished product in our hands because it was too dangerous. We had to fact-check everything because if they made mistakes, the industry would go after us and we could lose all our credibility. MiningWatch Canada does take placements now, but generally, the students work on discreet projects with other students, and they are supervised carefully by a professor we know and trust.

With GottaGo!, we don't have any staff. We don't have an office. We're just a gang of people [working to establish a network of public toilets in Ottawa] who really want to see this happen. We've had good experiences with students, but we don't care as much if they make a mistake. We've had wonderful students who, in fact, pushed things way ahead. The quality of the student made a huge difference. But it was sort of the luck of the draw.

Nancy: Why do you think community partners and organizations get involved, then, with student placements?

Joan: Talking about GottaGo!, there's research we need done that we don't have time to do ourselves. It's like having another volunteer for six months who is dedicated to this and has some skills. It can really expand the base of knowledge. It can get you access to people who have the ability to look information up or to do literature reviews. We get some young people interested in the issue, which matters by itself. They get excited and go back to the university and talk to everyone about the need for public toilets. That's worth it in terms of sharing knowledge and building energy. I would like to think that it will shift how they look at the world. For young people who have done placements at MiningWatch, their understanding of extractivism is deeply shifted by these projects. When you're trying to build a social movement, having more people thinking about justice, peace, and integrity creation is worth it. But the price that's paid is pretty enormous sometimes.

Nancy: That resonates with what I've heard from community partners - it's about providing students with an opportunity to learn about an organization or an issue, and building energy, like you said. 
Joan: It's wonderful. At Better Beginnings, we'd take students from diverse backgrounds because we wanted to make sure that the kids in the program saw their own diversity represented. It was important that there be lots of diversity in the staff, and where we were lacking diversity, student placements often made up for it. We would also take students who lived in the neighbourhood we were working in over anybody else. It enabled us to bring in neighbourhood people that we wouldn't have otherwise. A lot of the students who took social work courses were mature adults, and so we could bring one of the moms in as a placement student, and that was great.

You get some great students, but you can also get some terrible students; they're not interested in learning or their attitudes to people are just terrible. At Better Beginnings, we took a lot of placements because working with kids was something everybody thought they could do. But for some students, this wasn't really a field they should be working in, and we had very limited staff to deal with them. There were some really hair-raising moments.

Nancy: One of the things I've found, in that regard, is that students don't have the necessary training in the ethics of working in community contexts. They need to consider the ethical implications of their actions in the community, and when they don't, it can lead to some pretty hairy situations. What sort of training or preparation do you think students need?

Joan: One problem is that the placements are six months, if you're lucky. Most of the time, they're two and a half. That's really not long enough. In the length of time that students have in the community, I don't know how you'd do that kind of preparation or training without doubling the staff of the community organization. I think the only way for students to get the training is on the ground. And given how absolutely stressed most community organizations are, I don't know how they do that better, or if some kind of orientation is important, or if having a mentoring relationship with a key volunteer or a staff person would help.

Nancy: Do you have thoughts on journaling or other reflective tools that students use to gain critical perspective?

Joan: I'm not sure how I feel about journaling. I want to know what the prof is going to be reading in those journals if the students are journaling about what we're doing. There's a disturbing power relationship there, actually, in terms of community groups. I'm not asking the student to journal about their relationship with their prof. When I was supervising one student, I found myself thinking, "God, I wonder what she's saying about me," because I didn't know her prof very well.

Often the students are under pressure to do their journaling because that's how they get marked. One student we had was blocking on the journaling. There was nothing we 
could do about it. She had some kind of trauma about writing down what she was thinking and feeling about stuff. Sometimes, students' whole lives are being challenged by what they're seeing in the community. Some of them get trigged by what they're dealing with, too. It's difficult.

Nancy: On the other hand, sometimes students have difficulty finding something to write about. CSL instructors often assume that students need to be pushed out of their comfort zones, but what if that doesn't fit with what the community organization needs or has asked them to do? I had one student, for example, who was tasked with fixing computers at an organization. It was really useful for the community, but it didn't give him a lot of fodder for critical reflection. So there can be a tension, I think, between what the CSL model asks for and what the needs of the community are.

Joan: Yeah, that's a big one. Sometimes what community groups need isn't community-service people. They need technical people: engineers, geomaticians, computer experts, plumbers. The best student I ever worked with was a Geomatics student. She did a map of where all the municipally owned public toilets were in Ottawa and put them on GIS coordinates. And then we introduced her to the [city] councillor who was supporting us, and he ended up hiring her to do the mapping for the city. She was just extraordinary: she cared about the project, she fought for it, and she did a great job. Sometimes language skills can be very useful, too. Somebody who speaks Arabic or somebody who speaks Chinese can be crucial to an organization.

Nancy: This leads into my last question: how could community service-learning or other types of community-campus engagement be done in a way that is most beneficial to communities? Is there anything you would recommend?

Joan: We need to think about the long-term repercussions of these partnerships on the community. When I lived in Sudbury, there was a nine-month strike against the major mining company, Inco. There was a huge university project that was observing what was going on, writing things up, and doing interviews. There was a lot of engagement by these academics who cared about what was going on. But they were observing everything. They were observing the Wives Supporting the Strike meetings. They were observing union meetings. It's now a huge archive at Laurentian [University]. I don't think a single working person in the community has ever read that archive. But I know who does read it: it's the companies and other academics. There is now a record of everything we did to win that strike. That's concerning, because the information describing a struggle and how people organize themselves is freely available to the very people who will need to be opposed again in the future. That is disturbing in terms of what is being learned from communities and where that information goes. 
Nancy: How can we guard against this kind of exploitation?

Joan: There are times when organizing groups should just say no to researchers and students, quite frankly, because holding onto the data isn't enough. It's not enough to just say, "We want the data." They need to say, "You can't do the study." I'm conscious of the power relationships that underlie all this. We desperately need the knowledge and training and analysis that comes out of university. We need it in the language and form we can use and understand. We need the students. But the price is sometimes just too high. I'm always trying to figure out how we get access to what the academy has that would work for us and how we keep from reproducing those power relationships in our communities. It's not easy. I think there's a real question about what we do and how we do it.

And underlying it all, again, is why are we doing it? In my mind, I think: whose side are you on? Are you on the side of the huge corporate forces of death and of the elites? In a province like Saskatchewan, are you on the side of the oil and the pharmaceutical and the agro-industrial complex? Or are you on the side of the Earth and the waters and the people? Because it is definitely a battle.

\section{About the Contributors}

Joan Kuyek is a life-long community organizer and adult educator. The founding National Coordinator of MiningWatch Canada from 1999-2009, she continues to work for communities affected by mining. She is the author of Community Organizing: A Holistic Approach (2011), and a number of other books and publications. Email: joankuyek@sympatico.ca

Nancy Van Styvendale is an Associate Professor in the Faculty of Native Studies (UofA) who researches in the fields of Indigenous North American Literatures; Indigenous carceral writing; and community-engaged learning. 